Nigerian Journal of Physiological Sciences 23 (1-2): 51 - 54 @Physiological Society of Nigeria, 2008

Available online/abstracted at http://www.bioline.org.br/np; www.ajol.info/journals.nips; www.cas.org

\title{
THE EFFECT OF ADMINISTRATION OF AMODIAQUINE ON SOME PARAMETERS OF NEUROBEHAVIOUR OF WISTAR RATS
}

\author{
M. B. EKONG, A. O. IGIRI, and O. E. MESEMBE \\ Department of Anatomy, Faculty of Basic Medical Sciences, University of Calabar, Calabar, Nigeria \\ Email: mbe_flashpoint@yahoo.com
}

\begin{abstract}
Summary: The effect of administration of Amodiaquine (AQ) on some parameters of neurobehaviour of Wistar rats was carried out. Twenty adult Wistar rats weighing between 160-190g were divided equally into four groups. Group 1 served as the control, while groups 2, 3 and 4 were the experimental groups. The control group received distilled water. Groups 2 and 3 were treated with $8.75 \mathrm{mg} / \mathrm{kg}$ and $17.50 \mathrm{mg} / \mathrm{kg}$ respectively of AQ for three days, while group 4 was treated with $8.75 \mathrm{mg} / \mathrm{kg}$ of AQ for six days. Neurobehaviour test using the open field was carried out twelve hours after the last administrations. There were no significant differences between the control and the experimental groups in total locomotor activity (TLA), central square duration (CSD), stretch-attend (SA) and defecation. In the central square frequency (CSF), group 3 was significantly $(\mathrm{P}<0.05)$ higher than all the groups, while the control was the same as group 4, but higher than group 2, with the difference not being significant. In conclusion, AQ increased TLA and exploration, while simultaneously reducing anxiety in Wistar rats and these were dose dependent.
\end{abstract}

Key Words: Amodiaquine, anxiety, exploration, neurobehaviour, total locomotor activity, Wistar rat.

\section{Introduction}

Amodiaquine (AQ) is a 4-aminoquinoline antimalarial drug with a similar mode of action to chloroquine. It is schizonticidal and possesses antipyretic and anti-inflammatory properties as well. It is effective against the erythrocytic stages of all four species of Plasmodium falciparum (Olliaro and Mussano, 2003). AQ like other 4-aminoquinolines accumulates in the lysosomes of the parasites and brings about loss of function, making the parasites unable to digest haemoglobin, which it depends upon for its energy. This drug binds to nucleoproteins of the parasites and inhibits its DNA and RNA polymerases (O'Neill et al, 1998). It generates free radicals in the form of AQ quinine immine and semi quinine immine which have been implicated in lipid peroxidation (Maggs et al, 1988).

AQ has been known to cause several adverse reactions (Maggs et al, 1988). Most of these reactions are not documented because of few scientific researches and the initial withdrawal of the drug. Furthermore adverse reactions reported previously were mainly associated with the prophylactic use of AQ and this led the World Health Organization to list AQ again as a drug for treatment of chloroquine-resistant falciparum malaria (Winstanley et al, 1990).
The reaction to this drug as it affects animals' locomotion, exploration and anxiety cannot be precisely inferred. Thus, special parameters like behaviours in the open field test' are used (Walsh and Cummins, 1976; Brown et al, 1999). Hence the aim of this work is to find the effect of AQ on the neurobehaviour of Wistar rats.

\section{Materials and Methods}

Twenty adult Wistar rats weighing between 160-190g were procured from the animal house of the Department of Anatomy, University of Calabar, Calabar. Systematic random sampling was used to assign the rats into four groups of five animals each. Two packets of AQ were procured from Karmel Pharmacy, Calabar. Each packet of AQ contained twelve blistered tablets of $153.1 \mathrm{mg}$ per tablet. The drugs were administered orally using orogastric tubes with distilled water as the vehicle. The dosage was in milligram per kilogram body weight $(\mathrm{mg} / \mathrm{kg})$, twice a day (twelve hourly), three days for groups 2 and 3, and six days for group 4. These are as shown in Table 1. Twelve hours after the last administrations, neurobehaviour test was carried out using the open field maze (Walsh and Cummins, 1976). 


\begin{tabular}{clc} 
Table 1: & Drug administration \\
\hline $\begin{array}{c}\text { Group } \\
(\mathrm{n}=5)\end{array}$ & $\begin{array}{l}\text { Dosage } \\
\text { Day }\end{array}$ & $\begin{array}{c}\text { Duration } \\
\text { (Day) }\end{array}$ \\
2 & $\begin{array}{l}\text { Distilled } \\
\text { water }\end{array}$ & 3 \\
$8.75 \mathrm{mg} / \mathrm{kg}$ & 3 \\
3 & $\begin{array}{l}\text { of AQ } \\
17.50 \mathrm{mg} / \mathrm{kg} \\
\text { of } \mathrm{AQ}\end{array}$ & 3 \\
4 & $\begin{array}{l}8.75 \mathrm{mg} / \mathrm{kg} \\
\text { of } \mathrm{AQ}\end{array}$ & 6 \\
\hline
\end{tabular}

The apparatus used for 'open field test' was constructed of white plywood of $72 \times 72 \mathrm{~cm}$ with $36 \mathrm{~cm}$ walls. One of the walls was clear Plexiglas, so the animals could be visible, and the floor lined with clear Plexiglas. Blue lines were drawn on the floor with a marker and this was visible through the clear Plexiglas floor. These lines divided the floor into sixteen $18 \mathrm{x}$ $18 \mathrm{~cm}$ squares. A central square of $18 \times 18 \mathrm{~cm}$ was drawn in the middle of the open field. The maze was located in a $1.8 \times 4.6 \mathrm{~cm}$ test room lit by a 60 -watt red lamp for background lighting.

Rats were carried to the test room in home cages and were handled by the base of their tails at all times. Each rat was placed in the proximal right-hand corner of the maze and allowed to explore the apparatus for five minutes. After the five-minute test, the rat was returned in its home cage and the open field was cleaned with $70 \%$ ethyl alcohol and permitted to dry before the introduction of the next rat. Behaviour was scored manually, and each trial was recorded for subsequent analysis using a video camera positioned above the apparatus. The counting was also done manually.

The following activities were carried out: frequency of line crossing; frequency of central square entry; central square duration; frequency of rearing; frequencies of stretch-attend; urination; and defecation. The neurobehaviour of the animals were determined for total locomotor activities, exploration and anxiety. Total locomotor activity is the sum of the frequency of line crossing and the frequency of rearing; exploratory behavior and anxiety is the sum of frequency of central square entry, and also thee sum of central square duration. Anxiety is the sum of frequency of stretch- attends, the sum of urination, and the sum of defecation (Walsh and Cummins, 1976; Brown et al, 1999).

\section{Statistical Analysis}

One-way analysis of variance (ANOVA) was used to compare the group's mean for the open field activities, for treatment or administration and their interactions. Thereafter post-hoc test using StudentNewman-Keuls was carried out to find the level of significance at $\mathrm{P}<0.05$. All the results are expressed as mean \pm standard error of mean (Mean \pm SEM).

\section{Results}

Total Locomotor activity (TLA): The control $(68.00 \pm 11.78)$ was lower than groups $2(92.20$ $\pm 6.09), 3(95.60 \pm 5.70)$ and $4(85.00 \pm 11.90)$, in all there was no significant difference $(\mathrm{P}<0.05)$ among the groups but there was significant difference between the groups and the control.

Central Square Frequency (CSD: The control $(1.20 \pm 0.73)$ was higher than groups $2(0.80 \pm$ $0.37)$, same with group $4(1.20 \pm 0.37)$, but significantly $(\mathrm{P}<0.05)$ lower than group $3(3.80$ \pm 0.37). Groups 2 and 4 were also significantly $(\mathrm{P}<0.05)$ lower than group 3 .

Central square Duration (CSD): The control $(2.85 \pm 2.01)$ was higher than groups $2(1.32 \pm$ $0.93)$ and $4(2.31 \pm 1.17)$ and lower than group $3(6.54 \pm 1.34)$. In all there was no significant $(\mathrm{P}<0.05)$ difference between the groups and the control.

Stretch-Attend (SA): The stretch-attend of the control $(2.00 \pm 0.89)$ was higher than the rest of the groups $(2: 1.00 \pm 0.63,3: 0.00 \pm 0.00,4: 0.60$ \pm 0.40). In all, there was no significant difference $(\mathrm{P}<0.05)$.

Urination: There was no urination in all the experimental groups and the control.

Defecation: Defecation in the control (1.20 \pm 1.20) was lower than groups $2(2.80 \pm 0.80)$ and $3(2.80 \pm 1.24)$ but not different from group 4 $(1.20 \pm 0.80)$. In all, there was no significant difference $(\mathrm{P}<0.05)$ between the groups. These are as seen in Table 2 . 
Amodiaquine and some neurobehaviour parameters

Table 2: summary of TLA, CSF, CSD, SA and defecation of rats treated with different doses AQ.

\begin{tabular}{llllccc}
\hline Group & Treatment & \multicolumn{1}{c}{ TLA } & \multicolumn{1}{c}{ CSF } & CSD & SA & Defecation \\
\hline 1 & Control & $68.00 \pm 11.78$ & $1.20 \pm 0.73$ & $2.85 \pm 2.01$ & $2.00 \pm 0.89$ & $1.20 \pm 1.20$ \\
2 & $\begin{array}{l}8.75 \mathrm{mg} / \mathrm{kg} \\
\text { of AQ }\end{array}$ & $92.20 \pm 6.09$ & $0.80 \pm 0.37^{* *}$ & $1.32 \pm 0.93$ & $1.00 \pm 0.63$ & $2.80 \pm 0.80$ \\
3 & $\begin{array}{l}17.50 \\
\mathrm{mg} / \mathrm{kg}\end{array}$ & $95.60 \pm 5.70$ & $3.80 \pm 0.37^{*}$ & $6.54 \pm 1.34$ & $0.00 \pm 0.00$ & $2.80 \pm 1.24$ \\
4 & $\begin{array}{l}8.75 \mathrm{mg} / \mathrm{kg} \\
\text { of AQ }\end{array}$ & $85.00 \pm 11.90$ & $1.20 \pm 0.37^{* *}$ & $2.31 \pm 1.17$ & $0.60 \pm 0.40$ & $1.20 \pm 0.80$ \\
\hline
\end{tabular}

\section{Discussion}

In Total Locomotor Activity (TLA) the control was lower than groups 2 and 3 treated with $8.75 \mathrm{mg} / \mathrm{kg}$ and $17.50 \mathrm{mg} / \mathrm{kg}$ of AQ for three days respectively, and group 4 treated with $8.75 \mathrm{mg} / \mathrm{kg}$ of AQ for six days. TLA is usually used as a measure of locomotor activity, but it also measures exploration. High frequencies of these behaviours indicate increased locomotion and exploration (Walsh and Cummins, 1976; Brown et al, 1999). As seen in this study, the treated groups had higher locomotor and exploratory activities than the control. The increased activity may be due to the reaction to AQ treatment. Tester-Dalderup (1984) reported agitation, aggressiveness, confusion, personality changes and psychotic symptoms when AQ was used.

The control was significantly $(\mathrm{P}<0.05)$ lower than group 3 in Central Square Frequency (CSF), but not in Central Square Duration (CSD). It was higher than groups 2 and 4 in both CSF and CSD, and the differences were however not significant, however in CSF, groups 2 and 4 were significantly $(\mathrm{P}<0.05)$ lower than group 3 . The number of central square entries and the duration of the time spent in the central square are measures of exploration behavior and anxiety. A high frequency/duration of these behaviours indicates high exploratory behavior and low anxiety levels (Walsh and Cummins, 1976; Brown et al, 1999). In this study, the group with the higher dose treatment showed increase in CSF and CSD compared to the control. This may be due to the adverse effect of the drug (Tester-Dalderup, 1984).

The Stretch-Attend (SA) of the control was higher than the rest of the groups. SA postures are "risk-assessment" behaviour which indicate that the animal is hesitant to move from its present location to the new position (Blanchard et al, 2001), and thus high frequencies of these activities indicates high level of anxiety. AQ causes lipid peroxidation and induced agranulocytosis (Maggs et al, 1988; Farombi, 2000). These had earlier been reported to result in agitation, aggressiveness, confusion, personality changes and psychotic symptoms in chronic doses (Tester-Dalderup, 1984) and involuntary movements in acute usage (Salako, 1984). The SA in this study was low compared to the control. This may be due to the adverse and stimulatory effects the drug might have had on the animals.

There was no urination in all the groups, while defecation in the control was lower than groups 2 and 3, but not different from group 4 . Defecation and urination are often used as measures of anxiety, but their validity as measures of anxiety has been questioned (Lister, 1990). Hall (1934) describes defecation and urination as indices of anxiety in rodents. However, Bindra and Thompson (1953) reported that there is no significant relation between fearfulness and urination and defecation as measured in the open field test though they regarded urination and defecation in a novel environment as signs of timidity. In this study, lack of urination and low defecation reflects the low anxiety of this drug as also seen in other activities carried out.

Amodiaquine is a 4-amino quinolone, which generates free radicals in the form of amodiaquine quinine immine and semi quinine immine. This has been implicated in lipid peroxidation (Maggs et al, 1988; Farombi, 2000). Peroxidation of lipid is responsible for damage to tissue in vivo (Mayes, 2000). Lipid function in the replacement of damaged or worn membranes and as electrical insulators, allow rapid propagation of depolarization waves along myelinated nerve (Mayes, 2000), while proteins, the working molecules of the cell, function in the maintenance and repair of worn tissues and the production of neurotransmitters and enzymes (Singh, 2002). Disruption of these functions may result in neurodegeneration, thus the brain may not function effectively, which may likely result in death. This may be the reason for the results obtained in this study. AQ also causes agitation, aggressiveness, confusion, personality changes and psychotic symptoms in chronic disease (Tester-Dalderup, 1984). 


\section{Conclusion}

AQ have been reported to cause different adverse effects on the nervous system, as in other works carried out, our result revealed that AQ caused increase TLA and exploration, and less anxiety in Wistar rats and this was dose dependent.

\section{References}

Bindra, D. and Thompson, W. R. 91953). Evaluation of defecation and urination as measures of fearfulness. J. Comp. Physiol. Psychol. 46; 43-45.

Blanchard, D. C., Griebel, G. and Blanchard, R. J. (2001). Mouse defensive behaviours: pharmacological and behavioural assays for anxiety and panic. Neuroscience. Behav. Rev. 25:205-218.

Brown, R. E., Corey, S. C. and Moore, A. K. (1999). Differences in measure of exoploration and fear in mhc-congenic C57BL/6J and B6-H-2K Mice. Behav. Gen. 26:263-271.

Farombi, E. O. (2000). Influence of Amodiaquine treatment on microsomal lipid peroxidation and antioxidant defence systems of rats. Pharmacol. Toxicol. 87(6):249-54.

Hall, C. S. (1934). Emotional behaviour in the rat. I Defecation and urination as measures of individual differences in emotionality. $J$. Comp. Psychol. 18; 382-403.

Lister, R. G. (1990). Ethologically-based animal models of anxiety disorders. Pharmacol. Ther. 46; 311340.

Maggs, J. L., Tingle, M. D., Kitteringham, N. R. and Park, B. K. (1988). Drug-protein conjugates-XIV. Mechanisms of formation of protein-arylating intermediates fro amodiaquine, a myelotoxin and hepatotoxin in man. Biochem. Pharmacol. 37(2):303-311.
Mayes, P. A. (2000). Lipid of physiologic significance In: Murray, R. K.; Granner, D. K., Mayes, P. A. and Rodwell, V. W. (eds) Harper's Biochemistry. $25^{\text {th }}$ ed: MecurantHall, New York, pp. 160-171.

Olliaro, P. and Mussano, P. (2003). Amodiaquine for Treating Malaria. The Cochrane Database of System Reviews, 2: In the Cochrane Library. Chichester UK: John Wiley and Sons, Ltd.

O’Neill, P. M., Bray, P. G., Hawley, S. R., Ward, S. A. and Park, B. K. (1998). Pharmacol. Ther. 77:29-58.

Salako, L. A. (1984). Toxicity and side effects of anti-malarials in Africa: a critical review. Bulletin of the WHO, 62 (Suppl.) 63-68.

Singh, I. (2002). Introduction to Neuroanatomy. Textbook of Human Neuroanatomy $6^{\text {th }}$ ed. Delhi: Jaypee Brothers Medical publishers (P) Ltd. Pp. 125.

Tester-Dalderup, D. B. M. (1984). Antiprotozoal drugs. In: Dukes MNG (ed) Meyler's Side Effects of Drugs. $10^{\text {th }}$ ed. Amsterdam: Elsevier Science Publishers BV. P. 966.

Walsh, R. N. and Cummins, R. A. (1976). The open-field test: a critical review. Psychol. Bullet. 83: 482-504.

Winstanley, P. A., Simooya, O., Kofi-Ekwe, J. M., Walker, O., Salako, L. A., Edwards, G. Orme, M. L. and Breckenridge, A. M. (1990). The disposition of amodiaquine in Zambians and Nigerians with malaria. $\mathrm{Br}$. J. Clin. Pharmacol. 29: 695-701. 